\title{
The Practicality and Scalability of Respooling 3-D printing Thermoplastics A Multidisciplinary Research Project by the Canino School of Engineering Technology at SUNY Canton (WIP)
}

\section{Mr. Matt Jamison Burnett,}

Matt Burnett is a native of the Adirondack Mountains of Northern NY state. Working in paint, video and environmental installation, Burnett's work explores the history, paradoxes and environmental dilemmas of nature/culture relationships.

Burnett is currently a Professor in the Graphic and Multimedia Design Program at the State University of New York Canton. In his "Sustainability Lecture Series" at Canton, Burnett combines interdisciplinary teaching with a broad spectrum of speakers from various disciplines. His guests have included scientists, economists, theologists, engineers, and activists. In 2015 Burnett hosted Bill McKibben, the founder of 350.org and author of "the Burnett graduated from SUNY Plattsburgh in 1999 with a BA in Fine Arts, and in 2006 with an MFA in Studio Arts from Maine College of Art. He has since exhibited his work across the United States and Internationally. In addition to painting, he is known for new media environmental installations in the Northeast US, including Mt. Desert Island, Saranac Lake, Portland ME, St. Lawrence University, and Weymouth Nova Scotia.

During 2017 he was a visiting fellow at Munich University of Applied Sciences, where he developed and auditioned his latest project, "Convergence."

He currently develops resources and workshops for 3-D printing, 3-D design and 3-D imaging. He has worked with several institutions on setting up 3-D resources and currently teaches courses on 3-D printing and Design at Munich University of Applied Science, St. Lawrence University and SUNY Canton

\section{Michael A Wilson, SUNY Canton}

My name is Michael Wilson. I attend SUNY Canton as a Graphic and Multimedia Design student earning my Bachelor of Science degree.

\section{Mr. Anthony Filoso, State University of New York, Canton}

I am a senior at SUNY Canton, I am a Business Management major with a minor in Sustainability. As apart of our project for ASEE, my focus has been on the financial feasibility of this project. 

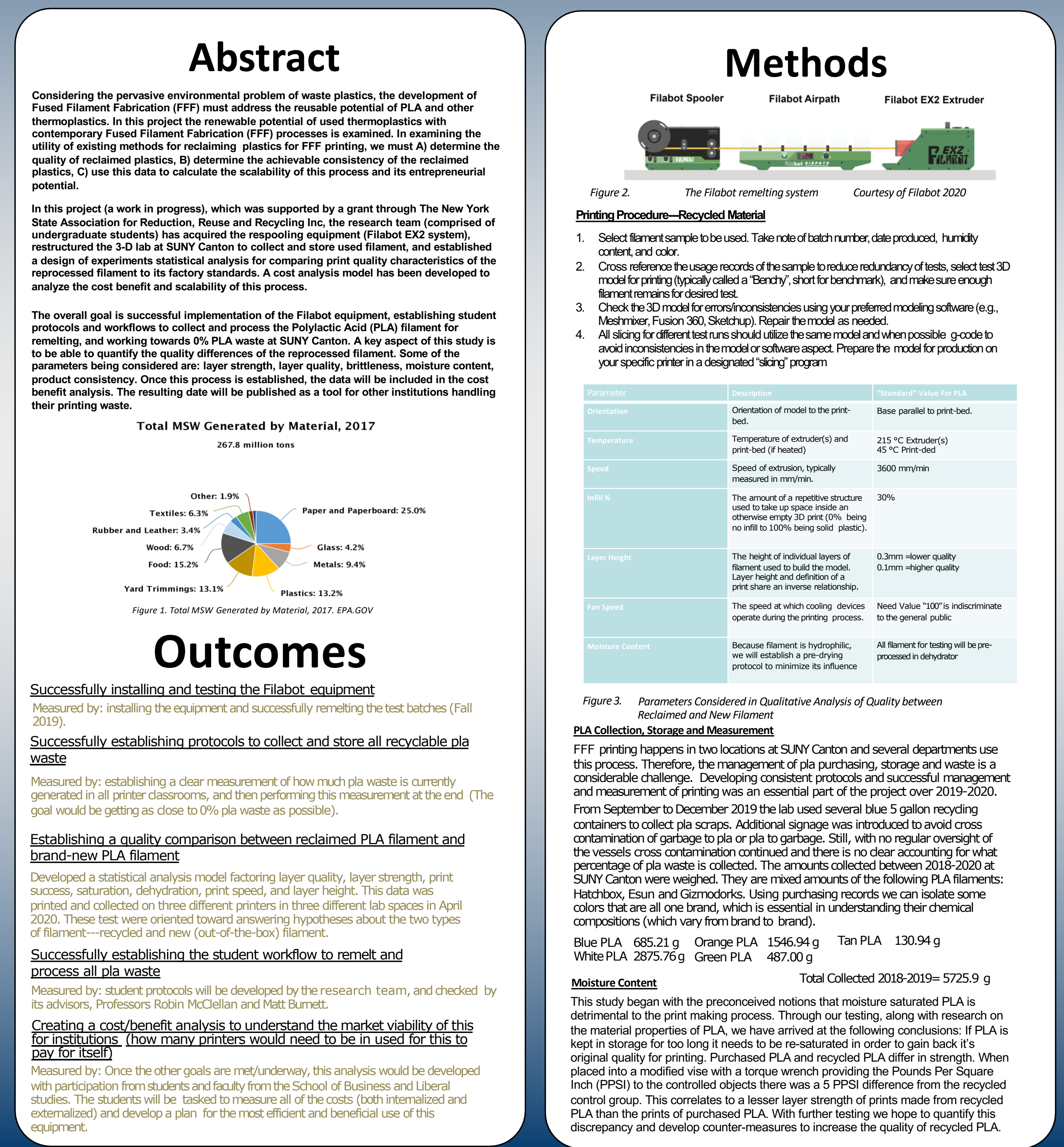

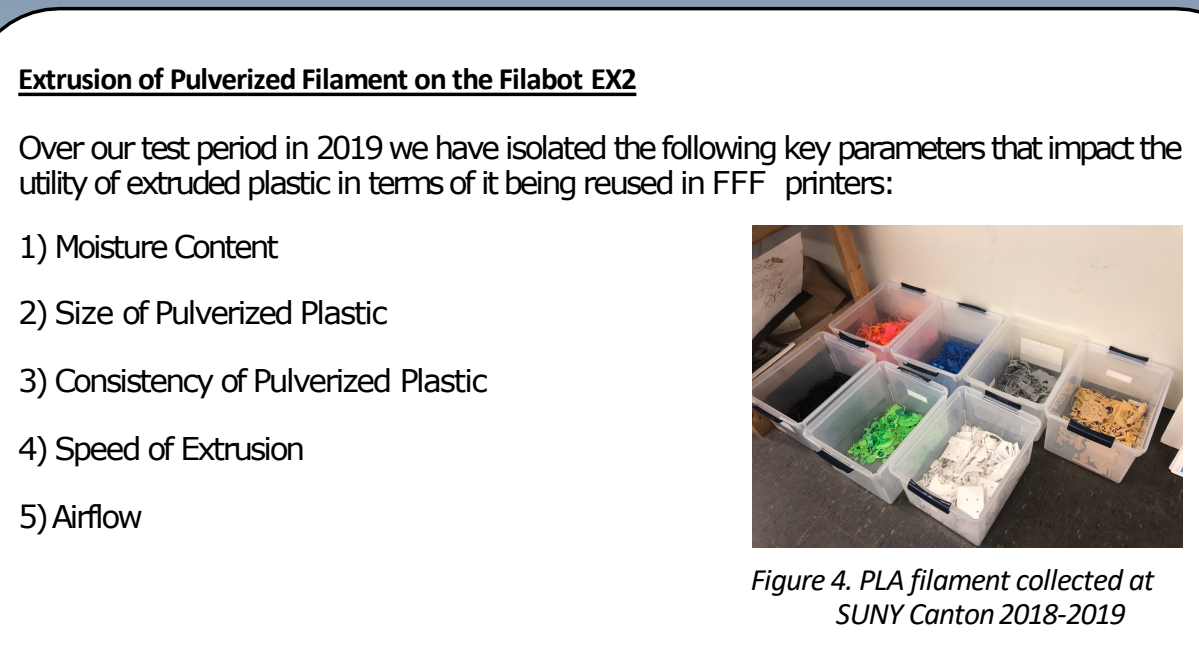

Further optimization is required in order to achieve a consistent diameter output. Being able
to measure, monitor, and reate consistent redaimed rolls of filament is crucial for utulity and Pulverization/Grinding of Plastic

The used filament comes in a variety fo densities
and sizes. We have used an industrial sized paper shredder and scissors to treducut the matereial toper consistent size, which is $\mathrm{s}$.
larger anounts of waste.

The mean amount of extrudable plastic pellets using
This method was 18 grams of pellets per person per

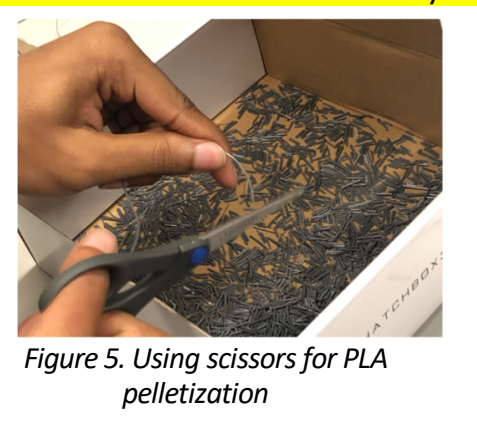

$\begin{array}{ll}\text { Ryobi Lawn and Leaf Shredder } & \begin{array}{l}\text { Inconsistent size output, frequent jams } \\ \text { reported }\end{array}\end{array}$

$\begin{array}{lll} & 3 \\ \text { Scissor Manual Reduction } & 18 \text { grams per person per hour } \\ \text { too slow, tedious }\end{array}$

Amazon Basics 15 sheet Cross Cut
Shredder

DIY Plastic Grinder

Can shred CDS, redit cards, other consurn
report utility for PLA
Too many variables and time demanding

INTBUYINGF $220 \mathrm{~V}$ Heavy
Duty Plastic Shredder Bottle

Too expensive, but may
be useful for scaling up

$\$ 1600$

Balancing cost and projected use, we chose the AmazonBasics 15 sheet Cross-Cut Paper

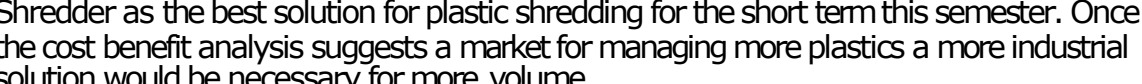

amentesis

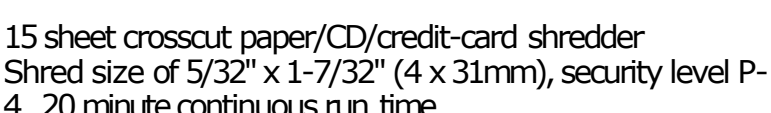

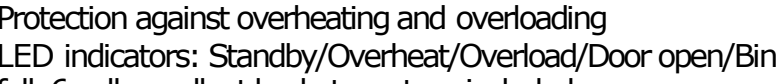
full 6 gallon pullout basket; casters indurded

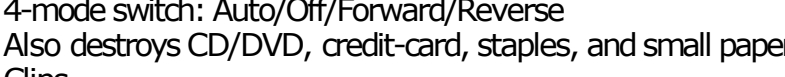

Refined Protocol for Filament Extrusion

1. Run pulverized flament through the dehydrator
Purroe the Filabot (using suppiled pellets)

Set temperaturet to $1100 \mathrm{C}$ C
Apply 1 cup of pulverized plastic

Apply 1 aup of pulverized plastc
Engage worm gear

Record ambient
Once exturing
Ond

II there is affaw noted, snip the roll, continue extruding and start a new roll
Record all information about time, temperature and machine settings and attach to the
Cost Benefit Analysis

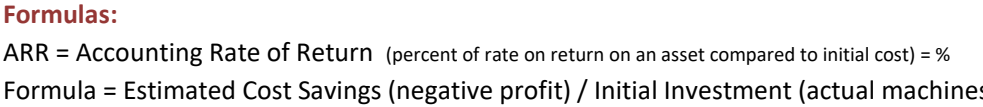

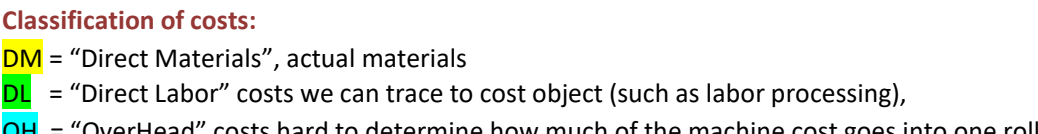

$\begin{array}{ll}\text { Benefits: } \\ \text { DM-Rol of recycled PLA } & =\$ 21 / \mathrm{Kg} \\ \text { DM- Savings on MSW disposal } \sim 5163 / \text { ton }=50.18 / \mathrm{Kg}\end{array}$

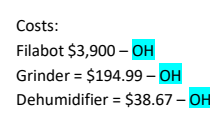

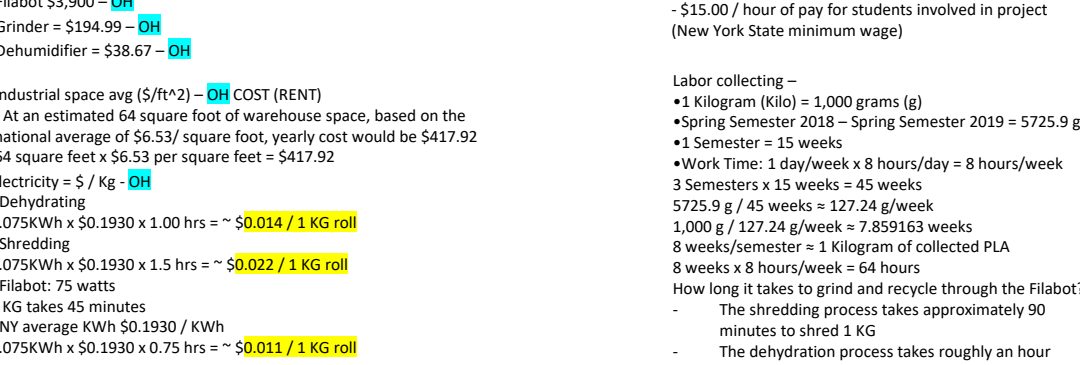

Conclusions

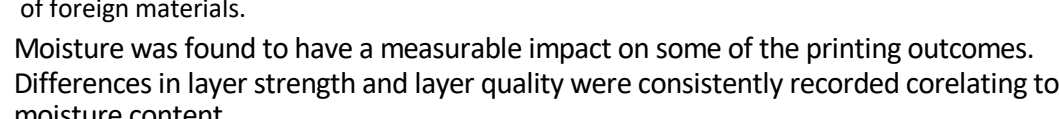

A. Completely dehydrating filament tid not in of itself vield the best printrig

B. Re-saturating filiment in water for 1.75 hrs (both new and recycled)

improved printing outcomes
C. Further testing is necessary to pinpoint the ideal moisture content for PLA

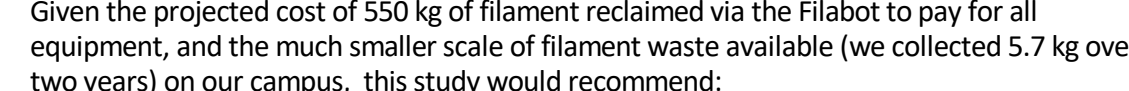

A. The qually dscrepancy between reclaimed filament and new filament significan

strength difference) must be addressed before it could be market ready.
The rechlimed filament might be useful even with reduced gualty for

printing and other inhouse uses.
c. At the present rate of consumption at Sunr Canton it it m more cost fffective to
continue purchasing new filiament rather then reprocessing used filament.

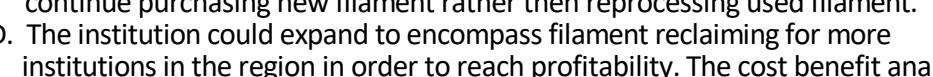

suggests that an increased production $x 96$ (547.2. Kg would cover equipmentr coss

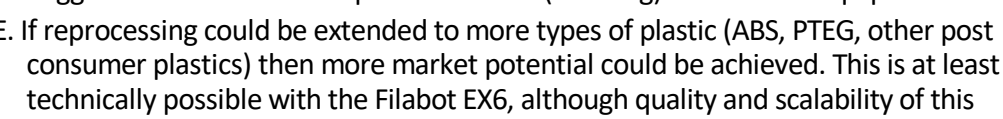

\section{Bibliography}

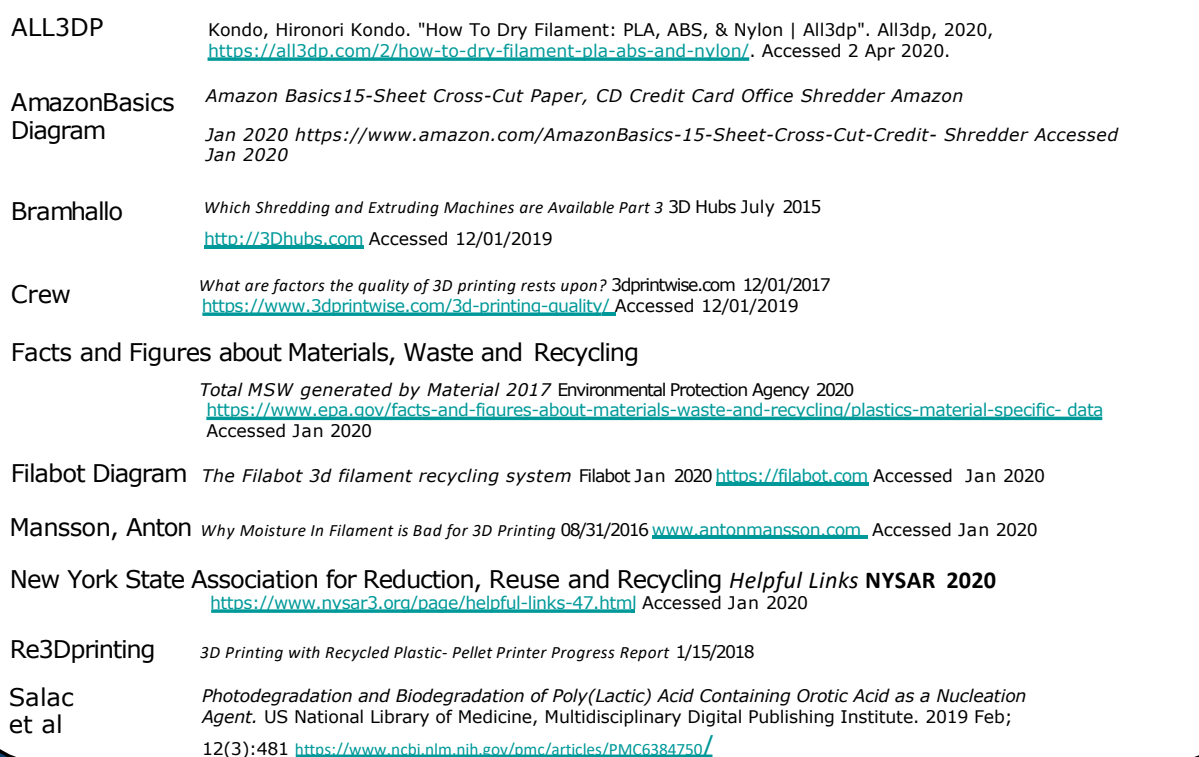

